\title{
SOX 2 Expression in Human Pituitary Adenomas-Correlations With Pituitary Function
}

\author{
CRISTINA CAPATINA ${ }^{1,2}$, ANCA MARIA CIMPEAN ${ }^{3,4}$, MARIUS RAICA ${ }^{3,4}$, \\ MIHAIL COCULESCU ${ }^{1,2}$ and CATALINA POIANA ${ }^{1,2}$ \\ ${ }^{1}$ Endocrinology Department, Carol Davila University of Medicine and Pharmacy, Bucharest, Romania; \\ ${ }^{2}$ CI Parhon National Institute of Endocrinology, Bucharest, Romania; \\ ${ }^{3}$ Department of Microscopic Morphology/Histology, \\ Victor Babes University of Medicine and Pharmacy, Timisoara, Romania; \\ ${ }^{4}$ Angiogenesis Research Center, Victor Babes University of Medicine and Pharmacy, Timisoara, Romania
}

\begin{abstract}
Background/Aim: The aim of this study was to evaluate SOX2 expression in pituitary adenomas and its correlation to their secretory state and clinicopathological parameters. Patients and Methods: Thirty-four patients were clinically evaluated and surgery was recommended for tumor removal. Histopathological diagnosis by hematoxylin eosin staining was followed by immunohistochemistry for pituitary hormones and SOX2 co-expression. Results: Fourteen of the 34 cases were $G H$-secreting adenomas, 10 were prolactinomas and 10 non-functioning pituitary adenomas. SOX2-positive expression was detected in $47.05 \%$ of total cases: $8 \mathrm{GH}$ secreting adenomas (57.14\%), 6 prolactinomas $(60 \%)$ and 2 non-functioning adenomas (20\%). SOX2 positivity was significantly higher amongst secreting adenomas $(p=0.041)$. SOX2-negative tumors were significantly associated with corticotrophin deficiency $(p=0.047)$ and gonadotrophin deficiency $(p=0.041)$. No correlation with tumor size or extrasellar extension was detected. Conclusion: SOX2 is differentially expressed in pituitary adenomas and influences the secretory state or clinical behavior of pituitary adenomas.
\end{abstract}

Pituitary adenomas (PA) represent at least $10 \%$ of all intracranial tumors. Despite their benign microscopic appearance, they are associated with an increased

This article is freely accessible online.

Correspondence to: Anca Maria Cimpean, MD, Ph.D., Hab.Dr.,"Victor Babeș" University of Medicine and Pharmacy, Department of Histology, Angiogenesis Research Center Timisoara, Piata Eftimie Murgu nr. 2, 300041, Timisoara, Timis, Romania. Tel: +40 720060955, e-mail: ancacimpean1972@yahoo.com

Key Words: SOX2, pituitary adenomas, secreting adenoma, nonfunctional pituitary adenoma. morbidity due to both compression and/or abnormal hormonal secretion. Most cases are diagnosed as macroadenomas and may be either non-functioning or associated with hormone hypersecretion, classified as secreting adenomas frequently prolactin (PRL), growth hormone $(\mathrm{GH})$ or adrenocorticotropic hormone (ACTH), rarely thyroid stimulating hormone (TSH), luteinizing hormone ( $\mathrm{LH})$, follicle stimulating hormone (FSH), occasionally co-secreting two or more hormones $(1,2)$.

Despite of their high prevalence, the mechanisms leading to PA are still elusive. This is partly due to the difficulty in sampling and culturing human pituitary tissue and the need to rely on animal models. To date, several mechanisms have been proposed including the involvement of various oncogenes, tumor suppressor genes and growth factors leading to PA development (3).

In the last decade, a growing number of research studies have focused on the presence of stem-like cells inside the normal pituitary gland and its corresponding tumors. SOX2, a member of the SOX family (SRY-related high mobility group (HMG) box), is a widely expressed marker of progenitor cells and stem cells in various organs, and functions as a transcription factor. The SOX2 gene is strongly expressed within the Rathke's pouch as well as in the neural ectoderm and exerts a critical role in the early stages of pituitary development (4). However, few SOX2-expressing cells are also present in normal human pituitary gland (5). The influence of these cells with a certified progenitor potential on pituitary neoplastic transformation has not yet been established. Also, an interrelation between the presence of these cells and the pituitary's functional state has not been evaluated. It has been demonstrated that SOX2 haploinsufficiency is associated with various degrees of hypopituitarism and anterior pituitary hypoplasia (4).

SOX2 expression in pituitary adenomas and its correlation with clinicopathological parameters (such as tumor 
aggressiveness or hypopituitarism) have not been investigated so far. Therefore, we aimed to evaluate SOX2 expression in pituitary adenomas related to their secretory state, in relation to clinicopathological parameters.

\section{Patients and Methods}

Patients selection and clinical evaluation. We retrospectively selected 34 patients diagnosed and followed-up in the Endocrinology Department of CI Parhon National Institute of Endocrinology, Bucharest, Romania. All these patients were recommended surgery for tumor removal. Tumors were harvested during surgical procedures. The pituitary function at the time of pituitary adenoma primary diagnosis was evaluated. We used the currently recommended criteria for the diagnosis of hypopituitarism (6). Based on published data, subjects with multiple pituitary hormone deficiencies were classified as $\mathrm{GH}$ deficient without the need of a GH-stimulation test (7). An informed consent was obtained from all patients before surgery.

Primary processing of collected tissues. Tumor samples were fixed in $10 \%$ buffered formalin for $24 \mathrm{~h}$ and paraffin embedded according to routine procedures. Three $\mu \mathrm{m}$ serial sections were performed and 10 slides were obtained from each case. Initial histopathologic diagnosis of pituitary adenomas was performed using hematoxylin and eosin staining followed by immunohistochemistry to classify pituitary adenomas according to hormone expression and assess SOX2 expression.

Immunohistochemistry. The slides were selected according to widely accepted rules of pre-analytical steps of immunohistochemistry. Quality control of the specimens was performed using immunostaining with vimentin, clone V9 (DAKO Cytomation, Carpinteria, CA, USA). A panel of six anti-pituitary hormone antibodies was used including: growth hormone (GH), PRL, ACTH, thyroid-stimulating hormone (TSH), follicle-stimulating hormone (FSH), and luteinizing hormone (LH) (DAKO).

Sections were incubated with polyclonal anti-SOX2 antibody (dilution 1:100, Abcam, Cambridge, MA, USA) for $2 \mathrm{~h}$ at room temperature. Colocalization of SOX2 with each of the six pituitary hormones was done by using a double immunostaining method based on combined Advance-Horseradish (HRP)/avidin-biotin/alkaline phosphatase (AP) (DAKO) technique using two different chromogens: 3, 3' diaminobenzidine for Advance-HRP method highlighting SOX2 as a brown staining restricted to nuclei and nitro-blue tetrazolium for avidin-biotin/AP highlighting cytoplasmic expression of pituitary hormones as dark blue staining with a granular pattern.

Microscopic evaluation and image acquisition. Microscopic examination was performed with Nikon Eclipse E 600 microscope (Nikon Corporation, Tokyo, Japan) and captured images were analyzed with Lucia G software system (Nikon Corporation).

Statistical analysis. Statistical analysis was performed using SPSS for Windows version 17.0 (SPSS Inc., Chicago, IL, USA). The Chisquare-test was applied for the comparisons of categories variables between the two subgroups of cases (SOX2 positive versus SOX2 negative tumors). $p$-Values below 0.05 were considered statistically significant.

\section{Results}

Cases included $14 \mathrm{GH}$-secreting tumors, 10 prolactin-secreting tumors (aggressive tumors, resistant to dopamine agonists, for which surgery had to be considered) and 10 non-functioning pituitary adenomas (NFPA). Three out of $14 \mathrm{GH}$-secreting tumors were microadenomas at the time of surgical resection, while all other studied tumors were macroadenomas (mean craniocaudal diameter $3.12 \mathrm{~cm}$, range $=0.5-5.4 \mathrm{~cm}$ ).

Surgery was recommended as initial treatment in the GHsecreting and NFPA while the 10 prolactinomas were large tumors (diameter $2.6-4 \mathrm{~cm}$, man diameter $3.38 \pm 0.52 \mathrm{~cm}$ ), resistant to dopamine agonists (defined as failure to normalize prolactin secretion and/or to decrease tumor size by at least $50 \%$, as in (8).

SOX2 positive expression was detected in 16 patients (47.05\% out of total cases). GH-secreting tumors were immuno-positive for SOX2 in $57.14 \%$ of cases, prolactinomas in $60 \%$ and non-functioning pituitary adenomas in only $20 \%$ of cases. Co-localization of SOX2 with pituitary hormones was mainly found in GH and PRL secreting adenomas (Figure $1 \mathrm{a}$ and $\mathrm{b}$ ).

The comparison between secreting and non-secreting tumors revealed a significantly higher percentage of SOX2 positivity amongst secreting tumors (Table I).

Among the $8 \mathrm{GH}$-secreting tumors expressing SOX2, 3 cases also expressed PRL and one case expressed also PRL and FSH. Six prolactinomas expressed only prolactin (4 cases) or associated synthesis of $\mathrm{GH}$ (without clinical expression) in 1 case and LH (in another) were also immunepositive for SOX2 protein. Both non-functioning adenomas expressing SOX2 were null-cell adenomas.

The comparison between SOX2 positive and negative tumor groups revealed no significant differences with respect to tumor volume or extrasellar extension at diagnosis (data not shown).

A percent of $58.82 \%$ of all patients (20 cases) had pituitary insufficiency at the time of initial diagnosis (5 cases with acromegaly, 7 prolactinomas and 8 NFPA). Most frequently affected was the gonadotrophic axis $(52.94 \%$ of all cases were deficient), followed by the thyrotrophic axis (47\% of cases had TSH deficiency) and corticotrophic (32.35\% of cases had ACTH deficiency). There was no difference in the percentages of cases with pituitary deficiency among the different subgroups of PA.

At the time of primary diagnosis, the percentage of corticotrophin and gonadotrophin deficiency was significantly higher in patients with SOX2 negative tumors compared to those with SOX2-positive tumors, while for thyrotropin deficiency reached no statistical significance (Table II).

In cases with associated hypopituitarism, the number of endocrine pituitary axes affected was not significantly different compared to SOX2 positive tumors (Table III). 


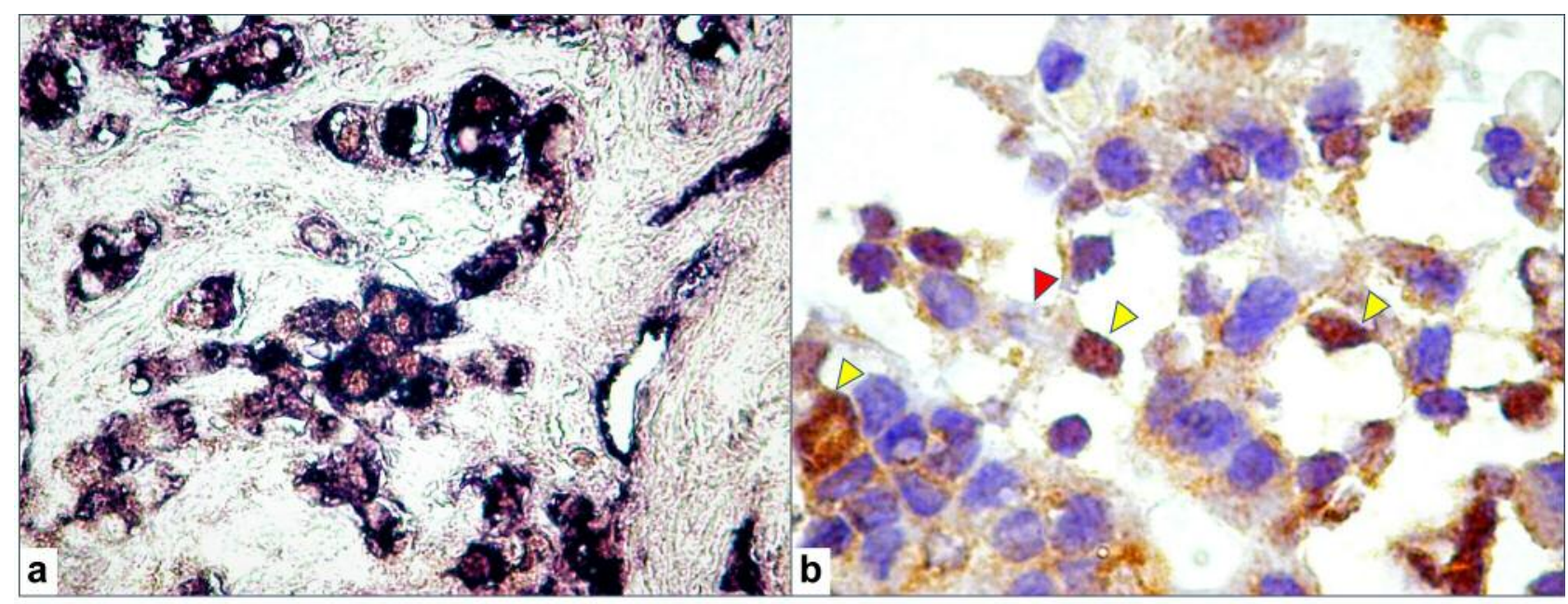

Figure 1. Double stain of tumor cells for SOX2 (brown, nuclear staining with 3,3'diaminobenzidine) and prolactin (blue, cytoplasmic staining with nitro-blue tetrazolium, (a). SOX2 expression in GH-secreting adenoma showing cells with SOX2-positive nuclei (yellow arrowheads), and with no GH expression (red arrowhead) suggesting that they may be cells at an incomplete differentiation state (b).

\section{Discussion}

After several attempts to identify pituitary stem or progenitor cells, some strong candidates have emerged (9). Among various cellular markers for pluripotency in the pituitary gland, the transcription factor SOX2 has an important role (10). SOX2 expression is maintained throughout the development of the anterior pituitary, but also in the adult gland. SOX2-positive stem cells were shown to contribute to pituitary ontogenesis as well as to growth and differentiation of the pituitary gland in the first weeks after birth, but later become dormant (11). In the adult, the expression of SOX2 is still detected in small populations of cells in the pituitary region and these cells retain the ability to differentiate into typical pituitary cells (12). When cultured in adequate culture media they demonstrate self-renewal and clonal expansion (13) and eventually differentiate into hormoneproducing cells (GH-, ACTH-, PRL-, gonadotropins-, and TSH), as well as follicle-stellate cells (12). However, most adult pituitary cells are not derived from SOX2-positive cells (14) and it is not established what drives the differentiation of the progenitor cells during late postnatal life.

It is possible that this ability to grow and differentiate explains, at least in part, the remarkable plasticity of the human adult pituitary gland- a tissue with the well-known ability to vary the proportion of various cell populations according to certain physiological demands (e.g. pregnancy, lactation or growth) (5). Experimental data suggest that cell differentiation from uncommitted progenitors explains this plasticity as well as cell repopulation following various types of damage to the pituitary gland (15). Our data suggest that
Table I. Percentage of SOX2-positive cells in secreting versus nonsecreting pituitary adenomas.

\begin{tabular}{lllc}
\hline Tumor type & $\begin{array}{c}\text { SOX2- } \\
\text { positive }\end{array}$ & $\begin{array}{c}\text { SOX2- } \\
\text { negative }\end{array}$ & $\begin{array}{c}p \text {-Value } \\
\text { (Chi-square test) }\end{array}$ \\
\hline Secreting & & & \\
GH-secreting & 57.14 & 42.85 & 0.489 \\
PRL-secreting & 60 & 40 & \\
All secreting tumors & 58.33 & 41.66 & $0.041^{*}$ \\
Non-secreting & 20 & 80 & \\
\hline
\end{tabular}

Table II. Percentage of SOX2-positive and SOX2-negative tumors associated with pituitary deficiency at diagnosis.

\begin{tabular}{lccc}
\hline & $\begin{array}{c}\text { SOX2- } \\
\text { positive }\end{array}$ & $\begin{array}{c}\text { SOX2- } \\
\text { negative }\end{array}$ & $p$-Value \\
\hline Any degree of hypopituitarism & & & \\
$\quad$ Present & 43.7 & 72.2 & $0.039^{*}$ \\
$\quad$ Absent & 56.2 & 27.7 & \\
Corticotrophin deficiency & & & \\
$\quad$ Present & 37.5 & 55.5 & $0.047^{*}$ \\
$\quad$ Absent & 62.5 & 44.5 & \\
Thyrotropin deficiency & & & \\
$\quad$ Present & 18.75 & 44.5 & 0.24 \\
$\quad$ Absent & 81.25 & 55.5 & \\
Gonadotrophin deficiency & & & \\
$\quad$ Present & 37.5 & 66.6 & $0.041^{*}$ \\
Absent & 62.5 & 33.3 & \\
\hline
\end{tabular}


Table III. Percentage of Sox2-positive and Sox2-negative tumors associated with pituitary deficiency.

\begin{tabular}{|c|c|c|c|c|c|}
\hline & $\begin{array}{c}\text { No } \\
\text { hypopituitarism }\end{array}$ & $\begin{array}{l}\text { One deficient } \\
\text { pituitary axis }\end{array}$ & $\begin{array}{l}\text { Two deficient } \\
\text { pituitary axes }\end{array}$ & $\begin{array}{l}\text { Three or more deficient } \\
\text { pituitary axes }\end{array}$ & $p$-Value \\
\hline SOX2-positive & 56.2 & 12.5 & 6.25 & 25 & 0.404 \\
\hline SOX2-negative & 27.7 & 11.1 & 22.2 & 38.8 & \\
\hline
\end{tabular}

it is possible that under certain conditions (for example in the case of compression of the normal pituitary and/or pituitary stalk in a patient with pituitary macroadenoma) these cells regain their ability to multiply and differentiate, protecting from pituitary insufficiency. The results of our study suggest the plausibility of such a mechanism. The small number of cases in our study also limits the power of our results and therefore this observation deserves further investigation.

The correlation between SOX2 positive status and gonadotrophic function is not surprising. In fact, SOX2 haploinsufficiency has been associated with various degrees of hypopituitarism and anterior pituitary hypoplasia, in both rodents and humans and in all cases the deficiency was restricted to the gonadotropins (4). Heterozygous de novo mutations in humans are also associated with gonadotrophin insufficiency together with severe ocular malformations and various other abnormalities (4). To our knowledge, no data are available related to the possible connection with corticotrophic function. It is possible that the prenatal expression of SOX2 (restricted to certain anatomical structures and time intervals) differs from the postnatal behavior of stimulated SOX2 positive cells.

The possible role of SOX2 expression in tumorigenesis has no convincing arguments yet. Generally speaking, somatic stem cells are present in various organs and have been putatively involved in tumorigenesis (16). Studies on human biopsies have demonstrated the presence of stem-like cells in pituitary tumors, as well as in mice $(5,17)$. In a previous study of our group, co-localization of SOX2 and prolactin was described in human prolactinomas (18). However, to our knowledge, there are no published data to support a possible role in pituitary tumor development. In contrast, in studies on craniopharyngioma, tumor-initiating mutations have been found in SOX2-positive pituitary cells. These cells are responsible for driving tumorigenesis in adult life, but are not the cells-of-origin of pituitary tumors (13). Our results did not reveal a difference in tumor characteristics (e.g. size, invasion at the time of diagnosis) related to SOX2 immunopositivity (as might intuitively be expected if such a role was significant). Also, our finding that secreting tumors are significantly more frequently SOX2-positive cannot be readily explained and its relevance should be further explored in larger studies.

\section{Conclusion}

SOX2-positive expression is frequent in pituitary adenomas (especially in secreting tumors), but is not correlated with tumor size or invasiveness. Lack of SOX2 expression is associated with a high percentage of pituitary insufficiency affecting several axes.

\section{Conflicts of Interest}

The Authors of the manuscript have no conflicts of interest to declare.

\section{References}

1 Jahangiri A, Wagner JR, Han SW, Tran MT, Miller LM, Chen R, Tom MW, Ostling LR, Kunwar S, Blevins L and Aghi MK: Improved versus worsened endocrine function after transsphenoidal surgery for nonfunctional pituitary adenomas: rate, time course, and radiological analysis. J Neurosurg 124 : 589-595, 2016.

2 Leenstra JL, Tanaka S, Kline RW, Brown PD, Link MJ, Nippoldt TB, Young WF Jr. and Pollock BE: Factors associated with endocrine deficits after stereotactic radiosurgery of pituitary adenomas. Neurosurgery 67: 27-32, 2010.

3 Bronstein MD and Melmed S: Pituitary tumorigenesis. Arq Bras Endocrinol Metabol 49: 615-625, 2005.

4 Kelberman D, de Castro SC, Huang S, Crolla JA, Palmer R, Gregory JW, Taylor D, Cavallo L, Faienza MF, Fischetto R, Achermann JC, Martinez-Barbera JP, Rizzoti K, Lovell-Badge R, Robinson IC, Gerrelli D and Dattani MT: SOX2 plays a critical role in the pituitary, forebrain, and eye during human embryonic development. J Clin Endocrinol Metab 93: 18651873,2008

5 Florio T: Adult pituitary stem cells: from pituitary plasticity to adenoma development. Neuroendocrinology 94: 265-277, 2011.

6 Fleseriu M, Hashim IA, Karavitaki N, Melmed S, Murad MH, Salvatori R and Samuels MH: Hormonal replacement in hypopituitarism in adults: an endocrine society clinical practice guideline. J Clin Endocrinol Metab 101: 3888-3921, 2016.

7 Hartman ML, Crowe BJ, Biller BM, Ho KK, Clemmons DR, Chipman JJ and Hypos CCSAB, Group USHS: Which patients do not require a GH stimulation test for the diagnosis of adult GH deficiency? J Clin Endocrinol Metab 87: 477-485, 2002.

8 Molitch ME: Management of medically refractory prolactinoma. J Neurooncol 117: 421-428, 2014. 
9 Gleiberman AS, Michurina T, Encinas JM, Roig JL, Krasnov P Balordi F, Fishell G, Rosenfeld MG and Enikolopov G: Genetic approaches identify adult pituitary stem cells. Proc Natl Acad Sci USA 105: 6332-6337, 2008.

10 Vankelecom $\mathrm{H}$ and Chen J: Pituitary stem cells: where do we stand? Mol Cell Endocrinol 385: 2-17, 2014.

$11 \mathrm{Zhu} \mathrm{X}$, Tollkuhn J, Taylor H and Rosenfeld MG: Notchdependent pituitary SOX2(+) stem cells exhibit a timed functional extinction in regulation of the postnatal gland. Stem Cell Reports 5: 1196-1209, 2015.

12 Fauquier T, Rizzoti K, Dattani M, Lovell-Badge R and Robinson IC: SOX2-expressing progenitor cells generate all of the major cell types in the adult mouse pituitary gland. Proc Natl Acad Sci USA 105: 2907-2912, 2008.

13 Andoniadou CL, Gaston-Massuet C, Reddy R, Schneider RP, Blasco MA, Le Tissier P, Jacques TS, Pevny LH, Dattani MT and Martinez-Barbera JP: Identification of novel pathways involved in the pathogenesis of human adamantinomatous craniopharyngioma. Acta Neuropathol 124: 259-271, 2012.

14 Taniguchi Y, Yasutaka S, Kominami R and Shinohara H: Proliferation and differentiation of rat anterior pituitary cells. Anat Embryol (Berl) 206: 1-11, 2002.
15 Vankelecom $\mathrm{H}$ and Gremeaux L: Stem cells in the pituitary gland: A burgeoning field. Gen Comp Endocrinol 166: 478-488, 2010.

16 Nguyen HT, Geens M and Spits C: Genetic and epigenetic instability in human pluripotent stem cells. Hum Reprod Update 19: 187-205, 2013.

17 Gao Z, Cai L, Lu J, Wang C, Li Q, Chen J, Song X, Chen X, Zhang L, Zheng W and Su Z: Expression of stem cell markers and dopamine D2 receptors in human and rat prolactinomas. Med Sci Monit 23: 1827-1833, 2017.

18 Cimpean AM, Raica $\mathrm{M}$ and Coculescu M: SOX2 as a stem/progenitor cel-associated marker in pituitary prolactinoma. Acta Endocrinologica (Buc) VI: 389-391, 2010.

Received September 20, 2018

Revised October 6, 2018

Accepted October 8, 2018 